\title{
Characterization of Natural Composites Fabricated from Abutilon-Fiber-Reinforced Poly (Lactic Acid)
}

\author{
Hua Wang ${ }^{1}$, Elwathig. A. M. Hassan ${ }^{2,3,4}$, Hafeezullah Memon ${ }^{2,5}{ }^{(}$, Tienah. H. H. Elagib ${ }^{3,4}$ and \\ Fadlelmoula Abad AllaIdris $4, *$ \\ 1 College of Textiles, Donghua University, 2999 North Renmin Road, Shanghai 201620, China \\ 2 Center for Civil Aviation Composites, Donghua University, 2999 North Renmin Road, \\ Shanghai 201620, China \\ 3 State Key Laboratory for Modification of Chemical Fibers and Polymer Materials, Donghua University, \\ Shanghai 200051, China \\ 4 Industries Engineering and Technology, University of Gezira, Wad Madani 21111, Sudan \\ 5 Key Laboratory of Textile Science \& Technology, Ministry of Education, College of Textiles, \\ Donghua University, 2999 North Renmin Road, Shanghai 201620, China \\ * Correspondence: fadlalmawala@uofg.edu.sd; Tel.: +249-11-3119-744
}

Received: 21 July 2019; Accepted: 28 August 2019; Published: 2 September 2019

\begin{abstract}
In recent decades, natural-fiber-reinforced poly (lactic acid) (PLA) composites have received a great deal of attention. In this study, biocomposites of poly (lactic acid) and abutilon fibers are prepared by using melt blending and an extruder. The effects of fiber additions on rheological, thermomechanical, thermal, and morphological properties are investigated using a rheometer, dynamic mechanical analysis (DMA), differential scanning calorimeter (DSC), TGA, and SEM, respectively. The DSC results indicate that the fibers acted as a nucleating agent, which led to enhancing the crystallization of PLA. The results also reveal that the thermal stability of PLA was improved by abutilon fibers. Moreover, higher values of storage modulus are observed, which are attributed to strong interfacial adhesion. In addition, thetan delta isreduced upon the addition of fiber content into the PLA matrix, which restricts the mobility of PLA polymer molecules in the presence of the fibers. The improvement of the properties and energy absorption capabilities of such biocomposites signifies the great potential of abutilon fibers as reinforcement in green composites.
\end{abstract}

Keywords: abutilon; green composite; characterization; poly (lactic acid) and reinforcement

\section{Introduction}

Natural-fiber-reinforced composites are widely used and are replacing synthetic fiber-reinforced polymers, especially for industrial applications such as biomedical instruments, biodegradable packaging, buildings, and automobiles [1-5]. Natural fibers generated from agriculture residue are considered to be renewable resources and have gained more attention than their counterparts due to their various advantages, which include but are not limited to lower-cost, obtain ability, recyclability, and biodegradability, as well as possessing eco-friendly characteristics compared to other fibers. It is promising to produce composites from natural fibers using different types of matrices, such as clay [6], cement [7], polypropylene (PP), polyethylene (PE), poly(lactic acid) (PLA), and poly(vinyl chloride) (PVC) [8], as they can satisfy any engineering application in terms of energy, strength, and absorption $[9,10]$. PLA is a synthetic aliphatic polyester produced from products of renewable crops (e.g., sugarcane, sugar beet, maize, and cassava) [11]. PLA has many applications in, for example, biomedical instruments, biodegradable packaging, and automotive industries [4]. It has been stated that PLA has an advantage over other polymers produced from oil. One advantage is its rapid 
biodegradation, which takes about 180 days to degrade completely [12,13]. The process is simple, non-toxic, eco-friendly, and widely applicable tothe industrial scale [14].

Many researchers have studied the mechanical behaviors of natural fibers blended with different thermoplastics (e.g., poly (lactic acid) and polyhydroxyalkanoate). Several studies on natural-fiber-reinforced biocomposites revealed that the mechanical properties of these biocomposites depend mainly on the adhesion between the fiber and the matrix [15]. In addition, different types of fiber, such as cotton linters, maple hardwood [16], and lyocell [4], were used. Most of these studies revealed that properties such as tensile and flexural strengths were improved. Liu et al. [17] found that the sizing of basalt fibers significantly increased the tensile strength, bending, and impact resistance of PLA. Iandas et al. [18] investigated a biocomposite generated from PLA/banana fibers by compression molding after melt mixing; their morphology analysis indicated a significant improvement of surface wetting and adhesion properties. A study conducted by Huda et al. [19] examined a PLA/recycled cellulose composite produced by injection molding and extrusion and found that up to a $30 \%$ addition of the filler significantly improved the rigidity of the composites without hindering the thermal stabilityand degree of crystallinity.

Abutilon fiber (Abutilon indicum, a small herb in the Malvaceae family) is a lignocellulose filler that is an underutilized agricultural waste product found in massive quantities in Sudan. Presently, it is mostly disposed of by burning, which increases the amount of carbon dioxide in the atmosphere. It was reported that lignocellulose fillers have a lower mass-to-volume ratio, less friction to mechanical parts, and are less expensive, less toxic, more eco-friendly, more renewable, and more biodegradable compared with inorganic fillers. For example, talc, kaolin calcium carbonate, and mica possess great potential to be studied and utilized as composites [20].

To reduce the environmental burden of the fiber and the cost, and due to its abundance as a renewable source and its biodegradability, PLA in particular, possesses highly promising properties, including recyclability, biodegradability, thermal insulation, and $\mathrm{CO}_{2}$ neutrality. It also has great potential over nonrenewable materials such as glass fibers and carbon fibers [21,22]. Furthermore, abutilon fibers (a widely grown indigenous Sudanese annual plant) have potential in many applications, such as biomedical instruments, buildings, packaging, and automobiles, although they have not yet been utilized in such ways.

In this work, the basic properties of abutilon fiber/PLA composites were studied for their suitability in different applications. Herein, 1, 3, and $5 \mathrm{wt} . \%$ of fiber loadings were incorporated into poly (lactic acid) to prepare fully environmentally friendly, sustainable, and biodegradable "green" composites. The effect of fiber content on the morphological, thermomechanical, rheological, and thermal properties of the composites was analyzed. It was found that the addition of fiber (filler) can be beneficial to enhance PLA composite properties. This composite can be applied to produce a large variety of composite materials, showing its potential in many industrial applications.

\section{Materials and Methods}

\subsection{Materials}

PLA in pellet form (4032D grade), with a weight-average molar weight of $\sim 60,000$ was supplied by Unic Technology (Suzhou) Co., Ltd., Suzhou, China. Abutilon fibers were collected from the agricultural farm at the University of Gezira, Wad Medani, Sudan. Acetone ( $\geq 99.5 \%)$ was supplied by Shanghai Yunli Economic and Trading Co., Ltd., Shanghai, China.

\subsection{Fiber Preparation}

Collected straws were rinsed with water to remove surface impurities and foreign particles. The straw bundles were retted to separate the fiber from the straw in channel water like a river for two weeks. After two weeks, the straw was removed from the water and the fibers were extracted manually by hand. The obtained fibers were cut into small pieces $(2-3 \mathrm{~mm})$ and washed with acetone to remove 
impurities in order to efficiently introduce the PLA layer and improve the compatibility between the matrix and the fibers. The physical and mechanical properties of abutilon fiber are comparable to those of jute fiber. The tensile strength of bundle jute fibers is $410 \mathrm{MPa}$ and elongation at break is $1.6 \%$

\subsection{Composite Preparation}

Before mixing, the fibers were dried at $70{ }^{\circ} \mathrm{C}$ for $24 \mathrm{~h}$ to adjust their moisture content; then, the fiber materials were used without any subsequent treatment. Composites with fiber contents of $1 \%, 3 \%$, and $5 \%$ were mixed using a high-speed mixer in a container and their blends were fed into a corotating twin-screw at $100 \mathrm{rpm}$ at $180-190{ }^{\circ} \mathrm{C}$ to obtain the granules. Afterward, the standard specimens were processed by injection. The injection molding temperature was $180-190^{\circ} \mathrm{C}$, at a pressure of $1 \mathrm{MPa}$, and a mold temperature of about $40^{\circ} \mathrm{C}$. A complete representation of the fiber and composite preparation is shown in Figure 1.

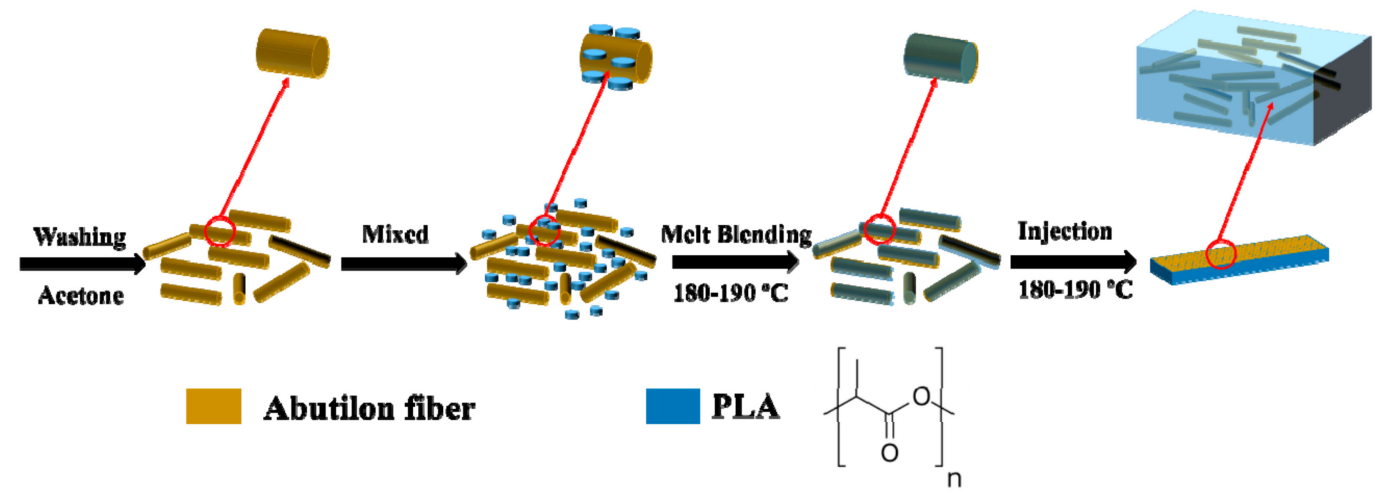

Figure 1. Scheme of fiber and composite preparation.

\subsection{Characterization}

The surface functional groups of PLA and the abutilon fibers were characterized by a FTIR spectrometer (Nicolet 8700 , Newcastle, DE, USA) using $\mathrm{KBr}$ disks in the wavenumbers ranging from 400 to $4000 \mathrm{~cm}^{-1}$. TGA was performed under a nitrogen atmosphere by using a TGA Q5000 IR (TA Instruments-Waters LLC, New Castle, DE, USA), with a sample weight of 3-5 mg and a temperature range of $30-450{ }^{\circ} \mathrm{C}$. The glass transition temperature $\left(\mathrm{T}_{\mathrm{g}}\right)$, crystallization temperature $\left(\mathrm{T}_{\mathrm{C}}\right)$, and melting temperature $\left(\mathrm{T}_{\mathrm{m}}\right)$ were monitored by the differential scanning calorimeter (DSC) Q 20 (TA Instrument-waters LLC, New Castle, DE USA) in the presence of $\mathrm{N}_{2}$. All the test specimens were oven-dried at $90{ }^{\circ} \mathrm{C}$ for $7 \mathrm{~h}$ before measurements to avoid the moisture effect. For DSC measurements, thermal characterization of the blends was performed at a sample weight of 5-10 $\mathrm{mg}$ and a temperature range of $30-200{ }^{\circ} \mathrm{C}$. The viscoelastic properties of the biocomposites were measured by dynamic mechanical analysis (DMA) (TA Q800, New Castle, DE, USA) at a frequency of $1 \mathrm{~Hz}$ and a strain rate of $0.1 \%$ by the dual-cantilever method at a temperature range of $30-130^{\circ} \mathrm{C}$ with a heating rate of $3{ }^{\circ} \mathrm{C} / \mathrm{min}$. The sizes of the rectangular specimens were $60 \times 7.5 \times 2.5 \mathrm{~mm}$ (Figure 2). The storage modulus, loss modulus, and tan delta of the specimens were measured as a function of temperature.

Rheological properties of pure resins and the blends were measured using the ARES-RFS TA instrument (Alzenau, Germany) at a frequency range of 0.1-100 rad/s under a nitrogen atmosphere. Before the measurement, all samples were vacuum oven-dried. The samples for rheological tests were prepared using injection molding at a temperature of $180^{\circ} \mathrm{C}$. The impact strength was determined by using an impact tester (Ceast Model 6545, Italy) according to ASTM D256 at $25^{\circ} \mathrm{C}$. All the reported results are an average of at least five measurements for each blending system. The surface morphology of the fractured composites was observed by SEM (HITACHI S-300N, Tokyo, Japan) with an acceleration voltage of $1.0 \mathrm{kV}$. 

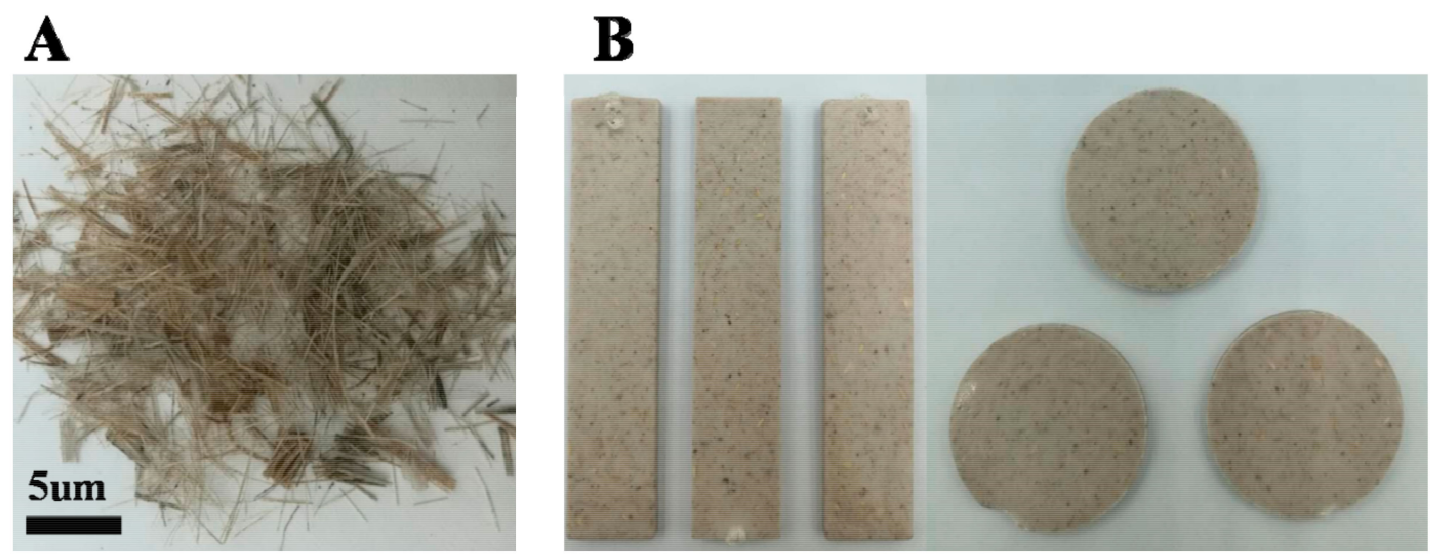

Figure 2. (A) Short abutilon fibers and (B) composite coupons for thermomechanical analysis.

\section{Results and Discussion}

\subsection{Fourier-Transform Infrared Spectroscopy}

Figure 3 shows the transmittance peaks related to chemical groups of abutilon fibers extracted from abutilon stems obtained by a FTIR spectrophotometer. The wave number was associated with the functional group; namely, wave numbers 3421 and $602 \mathrm{~cm}^{-1}$ were associated with the -OH group; $1049 \mathrm{~cm}^{-1}$ belonged to the $\mathrm{C}-\mathrm{O}$ group; $1629 \mathrm{~cm}^{-1}$ was associated with $\mathrm{C}=\mathrm{C}$, which was attributed to the aromatic skeletal vibration of lignin; $1737 \mathrm{~cm}^{-1}$ belonged to $\mathrm{C}=\mathrm{O}$ stretching, which pertained to acetyl or uranic ester; and $2925 \mathrm{~cm}^{-1}$ belonged to the $\mathrm{C}-\mathrm{H}$ stretching in an aromatic methyl group of cellulose and hemicellulose $[23,24]$. These results coincide with the results found by Silverstein [25].

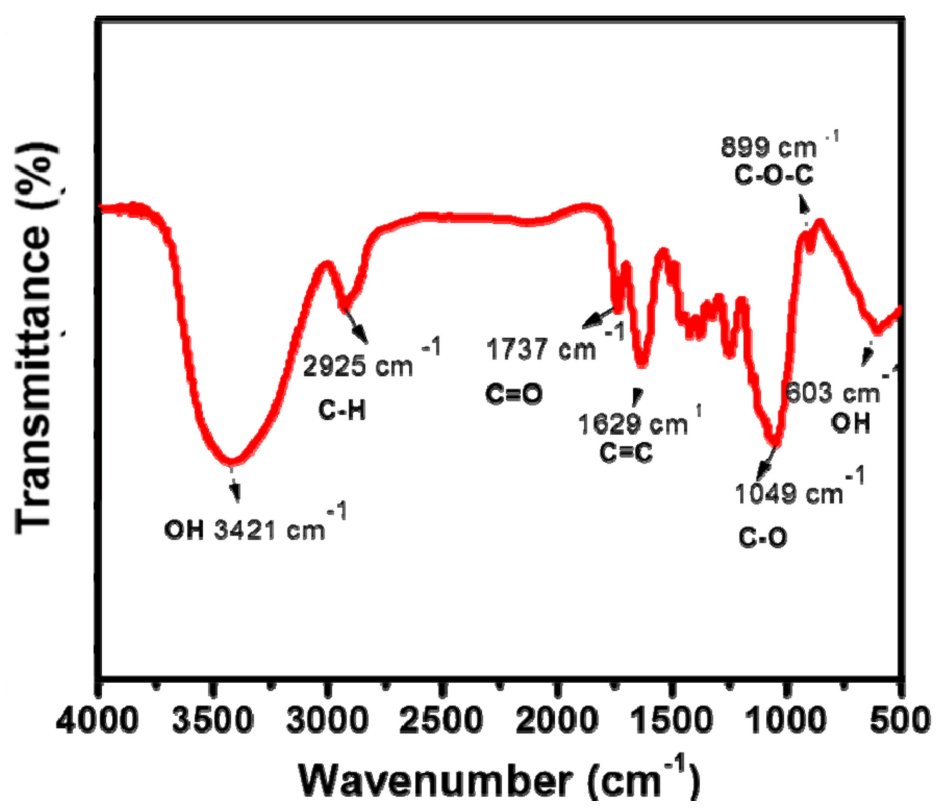

Figure 3. The FTIR spectra of abutilon fiber.

\subsection{Differential Scanning Calorimetry (DSC)}

The DSC curves of PLA and PLA/abutilon fiber with different contents are shown in Figure 4 . The graph displays the $T_{g}$, cold crystallization temperature $\left(T_{c}\right)$, and the $T_{m}$ of the tested material. Based on the crystal data, we observed that the addition of fiber $(1,3$, and 5 wt. $\%)$ to PLA improved the $T_{C}$. The composite of PLA/abutilon fiber (99/1) was recorded at $137{ }^{\circ} \mathrm{C}$, the composite of PLA/abutilon fiber $(97 / 3)$ was recorded at $132{ }^{\circ} \mathrm{C}$, and the highest value of $\mathrm{T}_{\mathrm{C}}$ at $141{ }^{\circ} \mathrm{C}$ was recorded at $5 \mathrm{wt}$. $\%$ of 
fiber added to a composite of PLA/abutilon fiber (95/5). These results indicate that the increase in $T_{C}$ of PLA reinforced with abutilon acted as a nucleating agent for PLA [26]. It was also noticed that there were two peaks of the melting point attributed to thin and thick lamella crystallinity. Upon the introduction of fibers to the PLA matrix, one of these peaks seemed to be reduced and shifted to a lower temperature, while the second peak remained, which indicated that the crystal structure changed from a less perfect to a more perfect structure. The melting peak did not obviously change with the addition of $1 \%$ or $3 \%$ of abutilon fiber to the PLA matrix, but a higher fiber weight $(95 / 5)$ yielded a higher melting point. The results also revealed that the $T_{g}$ disappeared. These phenomena may be due to improved crystallinity [27].

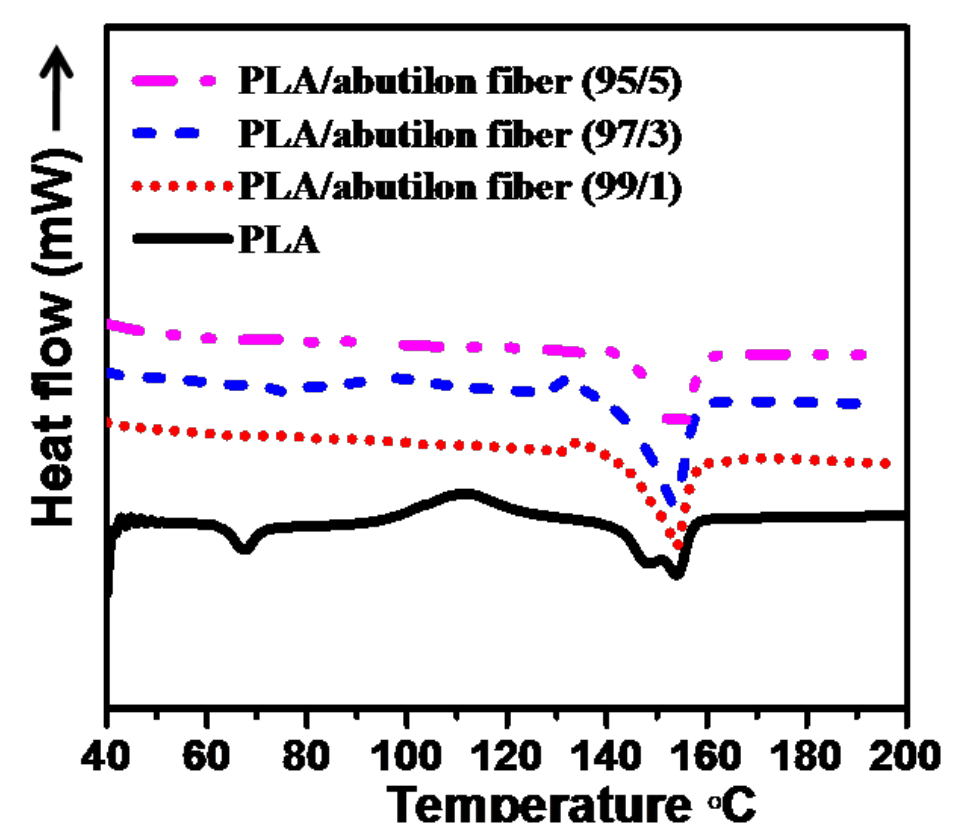

Figure 4. Differential scanning calorimetry of (PLA/abutilon fiber) composite.

\subsection{Thermogravimetric Analysis (TGA)}

Figure 5 shows the thermogravimetric curves illustrating the thermal degradation of pure PLA and PLA/abutilon fiber composites as a function of the temperature in a temperature range from 30 to $500{ }^{\circ} \mathrm{C}$. Three zones of degradation were observed. The first "initial" zone was related to the release of absorbed moisture from the sample. Thus, in this region, only small losses in weight were observed. On the other hand, sharp declines in weight were recorded primarily in the middle zone. The third zone was related to the further decomposition of mostly heavier organic compounds. According to Figure 5A, the TGA results of PLA/abutilon fiber revealed that the thermal degradation process of the PLA composites started prior to that of neat PLA, probably because of the inferior thermal stability of the fiber compared with the matrix. The increase in fiber weights did not affect the degradation process, since the curve of a different constituent of fiber weights of PLA/abutilon fiber composites did not show significant differences. The thermogravimetric curves for pure PLA and PLA/abutilon fiber composites depict a significant drop in the weight percentage near $250^{\circ} \mathrm{C}$ due to substantial material degradation. Moreover, a second transition in the curve was observed starting at about $360{ }^{\circ} \mathrm{C}$ and may be due to the initiation of material decomposition. From the differential thermal gravimetry (DTG) of the TGA (Figure 5B), it is found that the initial decomposition temperature of PLA decreasing with adding the fiber into PLA. The results revealed that the thermal stability decreased upon the addition of fiber into PLA due to the lower thermal stability of the fiber. These results agree with the results found in $[23,28]$. 
A

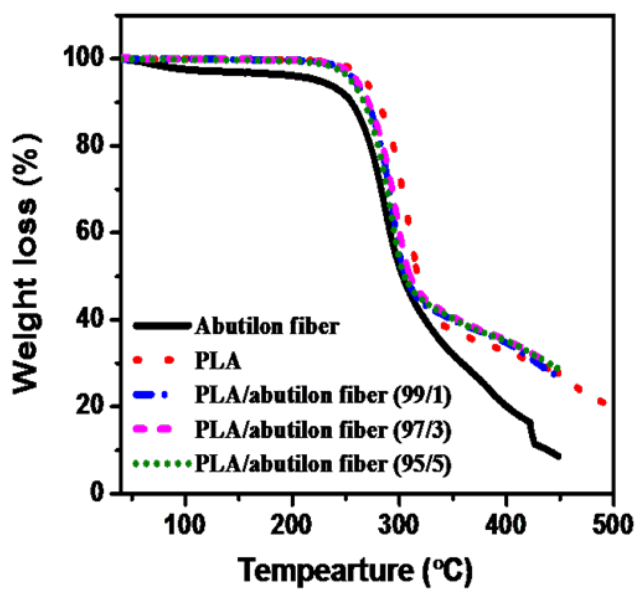

B

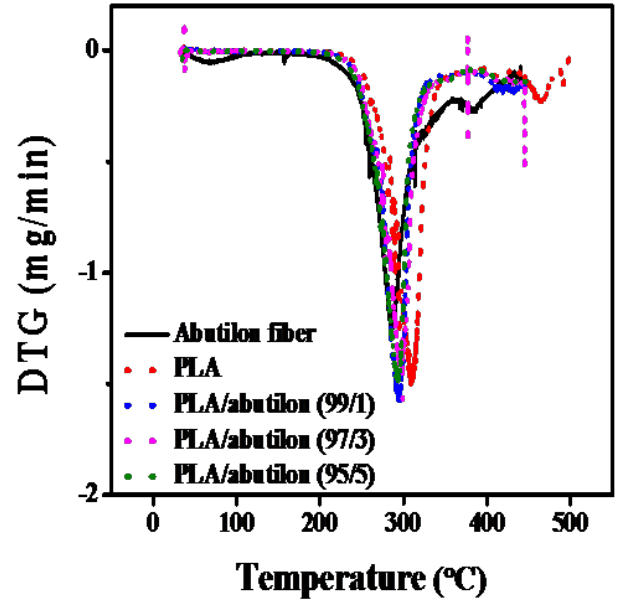

Figure 5. (A) TGA and differential thermal gravimetry and (B) DTG of composite-reinforced abutilon fiber and PLA/abutilon fiber.

\subsection{Dynamic Mechanical Analysis (DMA)}

The stiffness of the PLA/abutilon fiber composites as a function of temperature was studied by DMA. The values of the storage modulus, loss modulus, and tan delta for pure PLA and PLA/abutilon fiber composites with different weight contents were compared in a temperature range from 40 to $140{ }^{\circ} \mathrm{C}$. Figure 6 shows that pure PLA had a lower storage modulus compared with the PLA/abutilon fiber composite at room temperature. The storage modulus was directly proportional to the fiber content in PLA/abutilon fiber composites. In theory, the stress was transferred from the PLA matrix to the fiber, thus hindering the mobility and deformation of the matrix, and these results agree with those of a previous study [29]. Figure 7 illustrates the loss modulus curve. The addition of fiber weight $(1,3$, and $5 \mathrm{wt} . \%)$ improved the loss modulus of the composite (PLA/abutilon fiber) substantially. The tan deltacurves for pure PLA and PLA/abutilon fiber composites are presented in Figure 8. The addition of fibers into the PLA matrix reduced the tan delta values. This phenomenon was due to the better interaction between the fiber and the PLA polymer resin [30-32]. In general, the hindrance in the transition region for deforming a material determines the inadequacy of the elasticity bythe dissipation of energy into heat during DMA due to the decrease in mobility of the polymer chain into the composites and the overcoming of mechanical losses by interfraction between molecular chains of the matrix and the fibers [33].

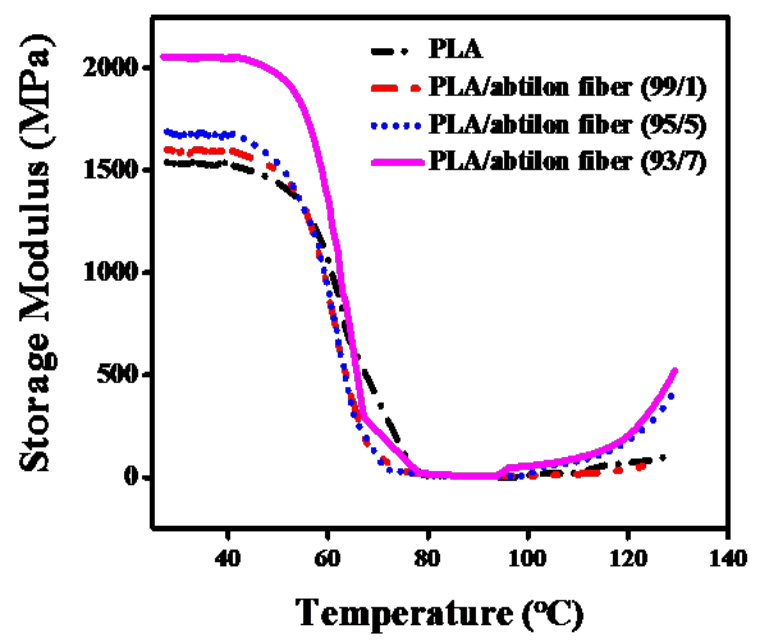

Figure 6. The storage modulus of the composite samples (PLA/abutilon fiber). 


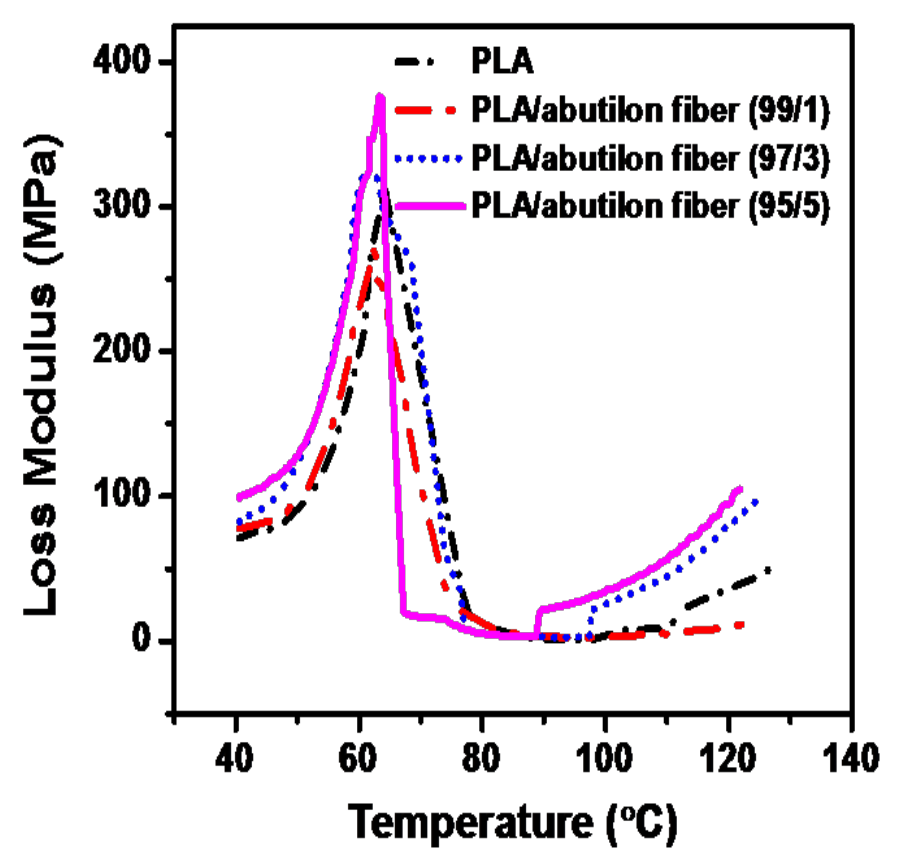

Figure 7. The loss modulus of the composite samples (PLA/abutilon fiber).

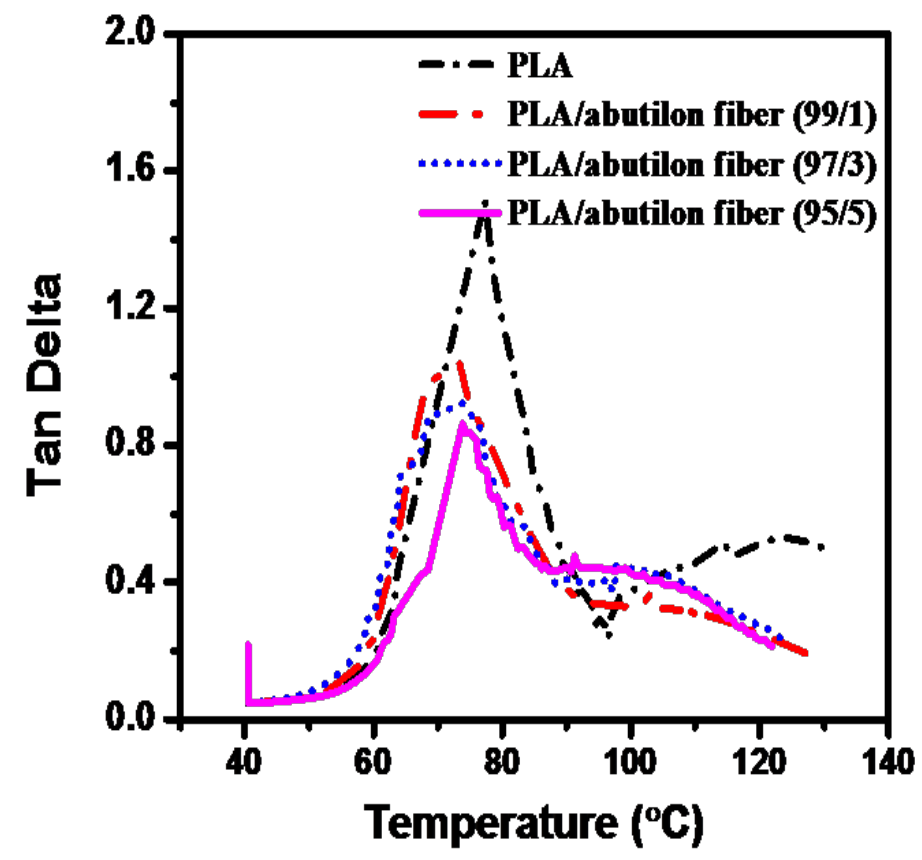

Figure 8. Tan delta of the composite samples (PLA/abutilon fiber).

\subsection{Rheological Properties}

Figures 9-11 show the frequency dependences of the storage modulus $\left(G^{\prime}\right)$, loss modulus $\left(G^{\prime \prime}\right)$, and viscosity of PLA and PLA/abutilon fiber blends with different fiber contents, respectively. As expected, increasing the angular frequency increased the storage modulus, loss modulus, and viscosity. The addition of fiber reduced $G^{\prime}$ and $G^{\prime \prime}$ due to significant short fiber distribution in the PLA matrix, which enlarged the distance among the PLA chains. The chain mobility of PLA was enhanced during the shearing action, and consequently, the storage modulus, loss modulus, and melt viscosity were reduced due to the plasticization of the PLA by volatiles given off from the partial decomposition of the fibers in the melt state. These results testify to the ability of the chains to flow better with increasing 
filler loading. Hence, the processability of the composites was influenced by the addition of fibers to the polymer melts.

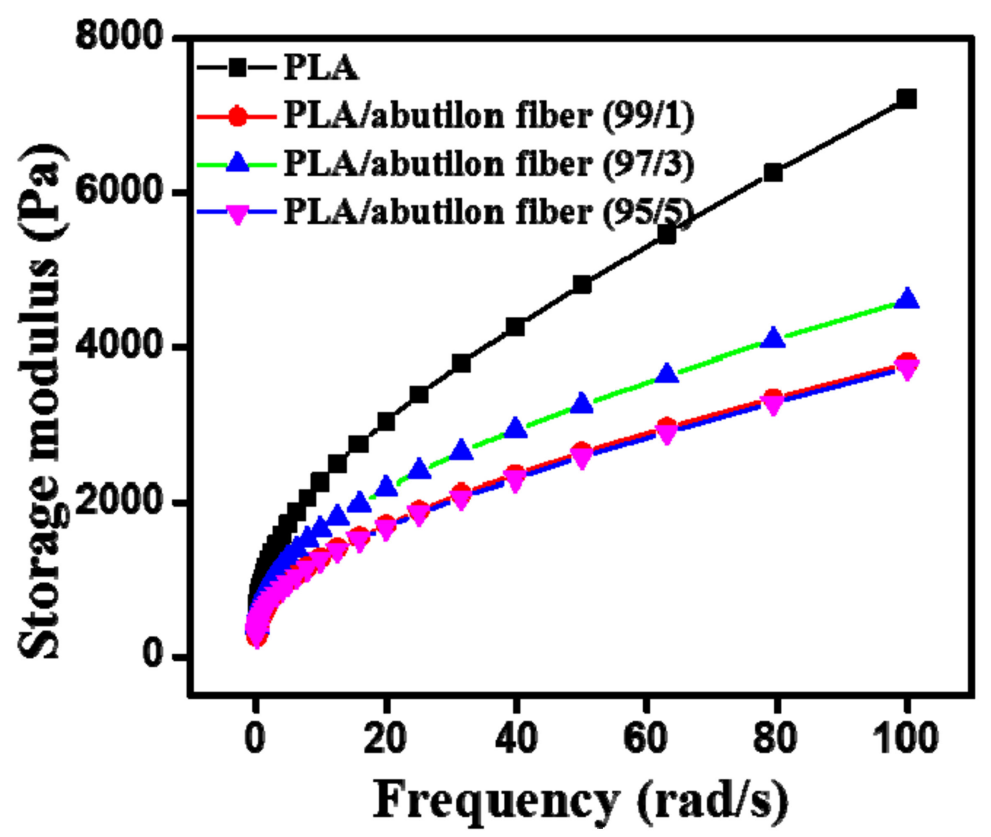

Figure 9. Storage modulus of (PLA/abutilon fiber) composites.

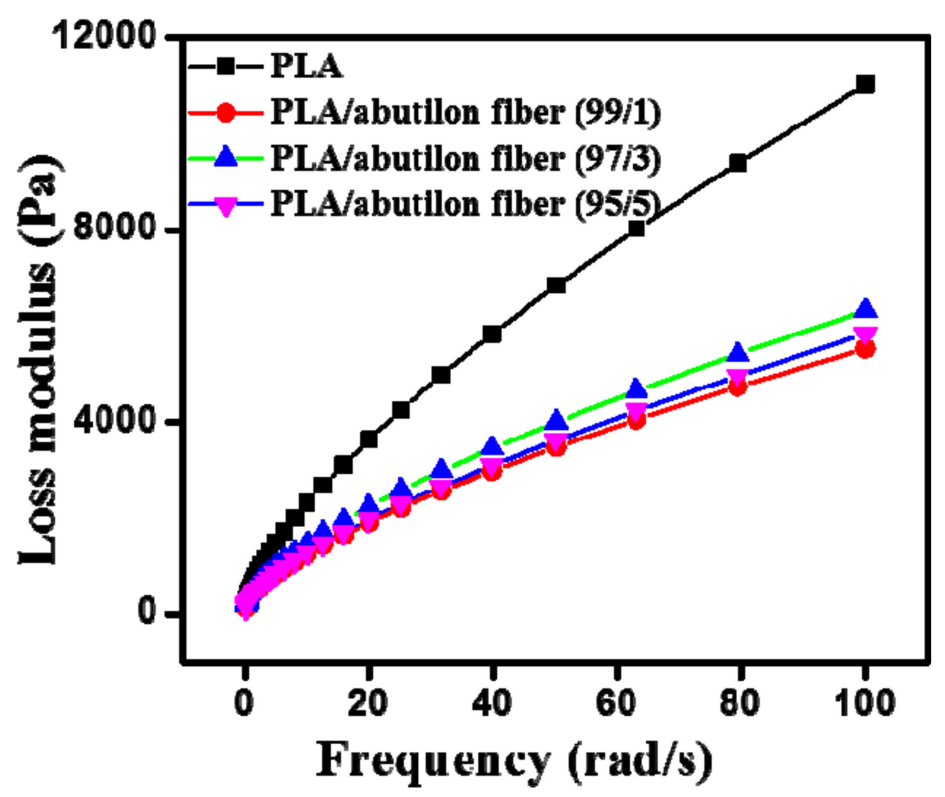

Figure 10. The loss modulus of (PLA/abutilon fiber) composites.

Moreover, the lower melt viscosity at a higher shear rate enabled lower injection pressure, less injection cycle time, and higher injection speed. The most significant result shown in the graphs is that the mentioned properties suddenly changed by increasing the abutilon fiber content from $1 \%$ to $3 \%$. These results suggest that the optimum processing conditions of the mixtures for shaping processes could be completely unlike those for the shaping processes of pure PLA. 


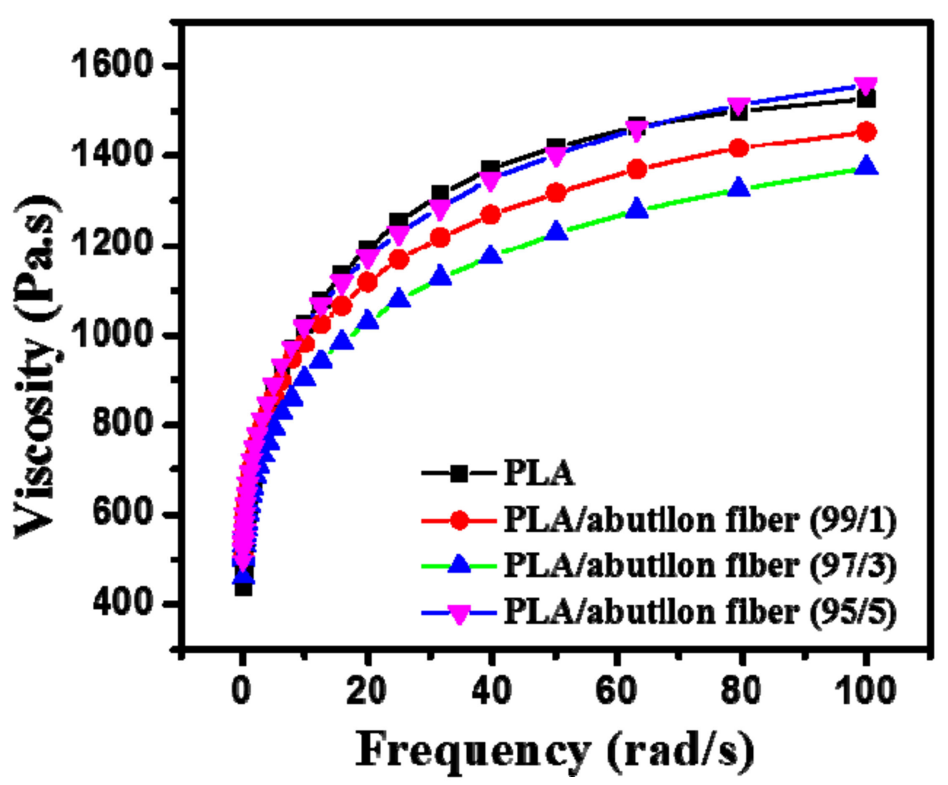

Figure 11. The viscosity of (PLA/abutilon fiber) composites.

\subsection{Impact Strength}

The impact strength of PLA/abutilon fiber composites is shown in Figure 12A. The impact strength of the composites was higher than neat PLA. It was found that by increasing the abutilon content, the impact strength linearly increased. The improvement in impact strength might have been due to a high number of fibers pulled out, which required more energy. This shows that incorporating abutilon fibers into PLA can greatly enhance its toughness. The addition of abutilon fiber significantly increased the tensile strength of PLA as shown in Figure 12B, it further increased with an increasing abutilon fiber ratio. The result indicated that the PLA can be successfully reinforced by fiber.
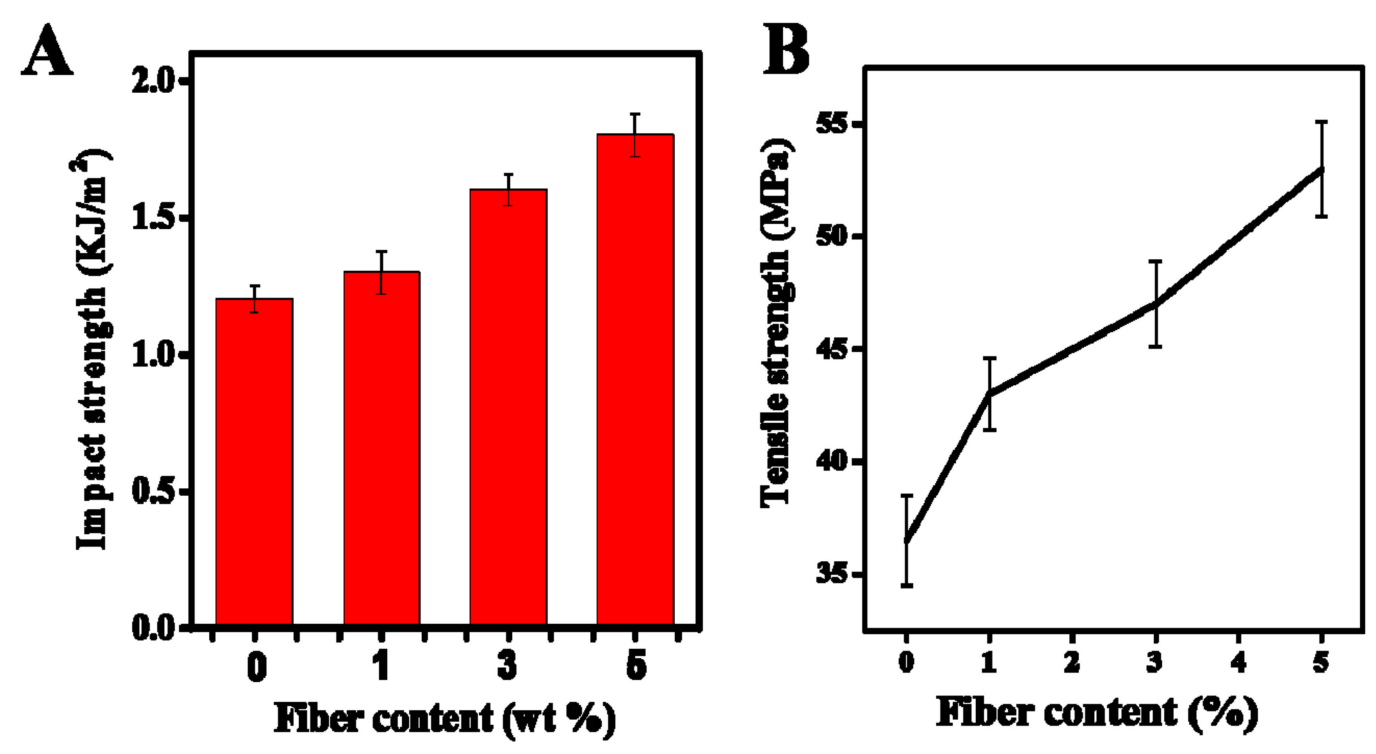

Figure 12. (A) Impact properties and (B) tensile strength of (PLA/abutilon fiber) composites.

\subsection{Surface Morphology}

The cross-sectional images of PLA and PLA/abutilon fiber composites were taken using SEM (Figure 13) to analyze the differences in their failure modes. The SEM image of pristine PLA presented in Figure 13A reveals a relatively smoother surface; however, the boundaries in the SEM image of pristine 
PLA presumably relate to the stress fracture due to brittleness as well as the lower crystallization of pure PLA. This suggests that most of the PLA molecular chains remained amorphous during melt mixing. The PLA/abutilon fiber composites presented in Figure 13B showed surface roughness since the fibers were attached to the PLA surface. As a result, there were some junctions and bulges on these composite surfaces. Moreover, some fibers pulled out due to lack of interaction between PLA and fiber as indicated by a circle. PLA displayed a brittle structure, whereas the presence of fiber in PLA showed a ductile formation.
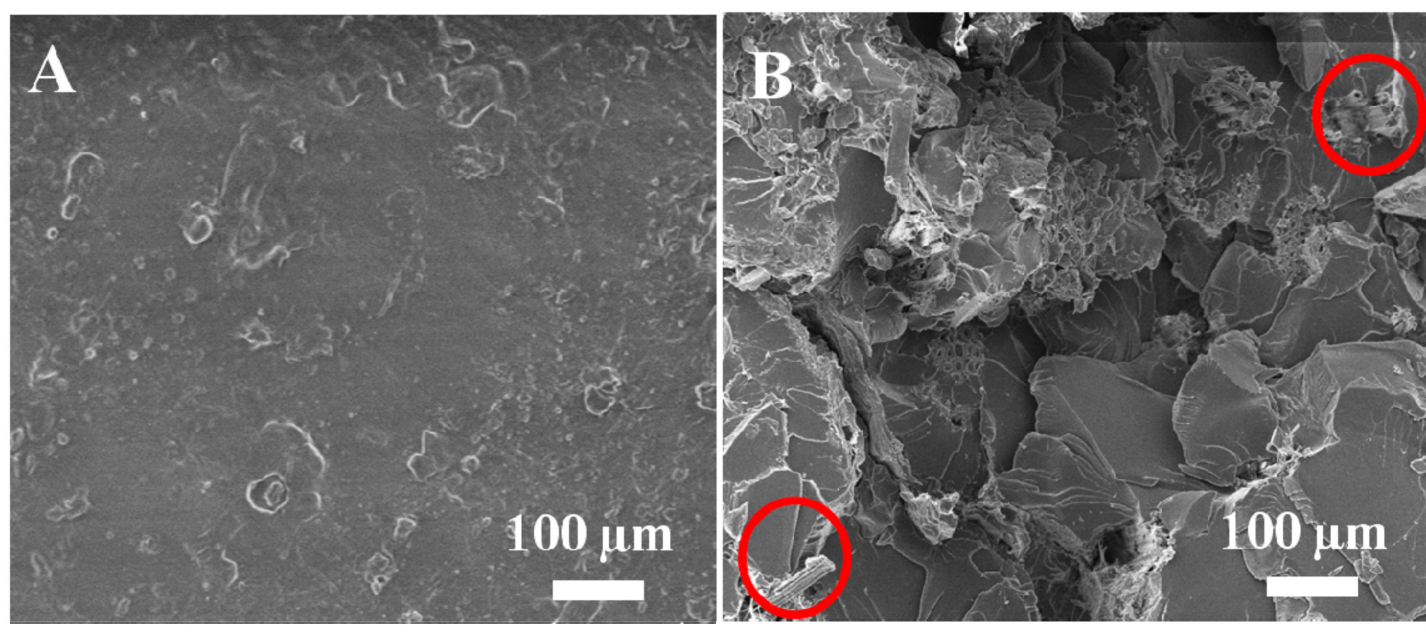

Figure 13. SEM images of pure PLA (A) and PLA/abutilon fiber (B).

\section{Conclusions}

In this study, different ratios of abutilon fibers were introduced into a PLA polymer to develop a green composite. The DSC results showed enhanced crystallizing when the reinforcement content was increased. TGA analysis confirmed the earlier initiation of the degradation process of pure PLA compared with the PLA composite. DMA showed that the storage modulus and loss modulus values for the PLA/abutilon fiber composites increased with the increasing amount of fiber. Further, the addition of fibers into the PLA matrix reduced the tan delta value due to the interfacial interactions between the fibers and the matrix. SEM observations of fractured surfaces of PLA/abutilon fiber composites indicated that good compatibility between matrix and fiber and, consequently, fiber-matrix debonding was not observed.The PLA/abutilon fiber composite can be used to produce large composite materials due to its good thermal properties and outstanding energy absorption capabilities, demonstrating the possibility of abutilon fibers being used as reinforcement in industrial applications. However, for its further usage in building applications, it will have to pass the necessary mechanical and interfacial adhesion tests.

Author Contributions: Conceptualization, W.H., E.A.M.H., and H.M.; methodology, W.H., F.A.I., and E.A.M.H.; validation, W.H., F.A.I., and H.M.; formal analysis, E.A.M.H., H.M., and F.A.I.; investigation, E.A.M.H., H.M., and F.A.I.; writing — original draft preparation, E.A.M.H., H.M., and F.A.I.; writing—review and editing, E.A.M.H. and T.H.H.E.

Funding: This research was sponsored by the Ministry of Higher Education and Scientific Research (Sudan). The authors greatly appreciate the sponsorship of the project. Our thanks are extended to Yu Mu Huo, Donghua University (P.R.C) for providing us with an opportunity to perform necessary composite fabrication and analysis at Donghua University.

Conflicts of Interest: The authors declare no conflicts of interest.

\section{References}

1. Wang, H.; Memon, H.A.M.; Hassan, E.; Miah, M.S.; Ali, M.A. Effect of Jute Fiber Modification on Mechanical Properties of Jute Fiber Composite. Materials 2019, 12, 1226. [CrossRef] [PubMed] 
2. Sepe, R.; Bollino, F.; Boccarusso, L.; Caputo, F. Influence of chemical treatments on mechanical properties of hemp fiber reinforced composites. Compos. Part B 2018, 133, 210-217. [CrossRef]

3. Pozzi, A.; Sepe, R. Mechanical properties of woven natural fiber reinforced composites. In Proceedings of the ECCM-15th European Conference on Composite Materials, Venice, Italy, 24-28 June 2012; pp. 1-11.

4. Graupner, N.; Herrmann, A.S.; Müssig, J. Natural and man-made cellulose fibre-reinforced poly (lactic acid) (PLA) composites: An overview about mechanical characteristics and application areas. Compos. Part A Appl. Sci. Manuf. 2009, 40, 810-821. [CrossRef]

5. Pickering, K. Institute of Materials, Mining, Properties and Performance of Natural-Fibre Composites; Woodhead Pub.: Cambridge, UK; CRC Press, Maney Pub.: Boca Raton, FL, USA, 2008.

6. Millogo, Y.; Morel, J.C.; Aubert, J.E.; Ghavami, K. Experimental analysis of pressed adobe blocks reinforced with Hibiscus cannabinus fibers. Constr. Build. Mater. 2014, 52, 71-78. [CrossRef]

7. Ali, M.; Chouw, N. Experimental investigations on coconut-fibre rope tensile strength and pullout from coconut fibre reinforced concrete. Constr. Build. Mater. 2013, 41, 681-690. [CrossRef]

8. Lei, Y.; Wu, Q.; Yao, F.; Xu, Y. Preparation and properties of recycled HDPE/natural fiber composites. Compos. Part A Appl. Sci. Manuf. 2007, 38, 1664-1674. [CrossRef]

9. Chen, X.; Yu, J.; Zhang, Z.; Lu, C. Study on structure and thermal stability properties of cellulose fibers from rice straw. Carbohydr. Polym. 2011, 85, 245-250. [CrossRef]

10. Lanzoni, L.; Nobili, A.; Tarantino, A. Performance evaluation of a polypropylene-based draw-wired fibre for concrete structures. Constr. Build. Mater. 2012, 28, 798-806. [CrossRef]

11. Armentano, I.; Bitinis, N.; Fortunati, E.; Mattioli, S.; Rescignano, N.; Verdejo, R.; Lopez-Manchado, M.; Kenny, J. Multifunctional nanostructured PLA materials for packaging and tissue engineering. Prog. Polym. Sci. 2013, 38, 1720-1747. [CrossRef]

12. Raquez, J.M.; Habibi, Y.; Murariu, M.; Dubois, P. Polylactide (PLA)-based nanocomposites. Prog. Polym. Sci. 2013, 38, 1504-1542. [CrossRef]

13. Harnnecker, F.; dos Santos Rosa, D.; Lenz, D.M. Biodegradable polyester-based blend reinforced with Curauá fiber: Thermal, mechanical and biodegradation behaviour. J. Polym. Environ. 2012, 20, 237-244. [CrossRef]

14. Datta, R.; Henry, M. Lactic acid: Recent advances in products, processes and technologies-A review. J. Chem. Technol. Biotechnol. Int. Res. Process Environ. Clean Technol. 2006, 81, 1119-1129. [CrossRef]

15. John, M.J.; Thomas, S. Biofibres and biocomposites. Carbohydr. Polym. 2008, 71, 343-364. [CrossRef]

16. Way, C.; Wu, D.Y.; Cram, D.; Dean, K.; Palombo, E. Processing stability and biodegradation of polylactic acid (PLA) composites reinforced with cotton linters or maple hardwood fibres. J. Polym. Environ. 2013, 21, 54-70. [CrossRef]

17. Liu, T.; Yu, F.; Yu, X.; Zhao, X.; Lu, A.; Wang, J. Basalt fiber reinforced and elastomer toughened polylactide composites: Mechanical properties, rheology, crystallization and morphology. J. Appl. Polym. Sci. 2012, 125, 1292-1301. [CrossRef]

18. Shih, Y.F.; Huang, C.C. Polylactic acid (PLA)/banana fiber (BF) biodegradable green composites. J. Polym. Res. 2011, 18, 2335-2340. [CrossRef]

19. Huda, M.S.; Drzal, L.T.; Mohanty, A.K.; Misra, M. Effect of fiber surface-treatments on the properties of laminated biocomposites from poly (lactic acid) (PLA) and kenaf fibers. Compos. Sci. Technol. 2008, 68, 424-432. [CrossRef]

20. Yaacab, N.D.; Ismail, H.; Ting, S.S. Potential use of paddy straw as filler in poly lactic acid/paddy straw powder biocomposite: Thermal and thermal properties. Procedia Chem. 2016, 19, 757-762. [CrossRef]

21. Bajpai, P.K.; Singh, I.; Madaan, J. Development and characterization of PLA-based green composites: A review. J. Thermoplast. Compos. Mater. 2014, 27, 52-81. [CrossRef]

22. Chard, J.M.; Creech, G.; Jesson, D.A.; Smith, P.A. Green composites: Sustainability and mechanical performance. Plast. Rubber Compos. 2013, 42, 421-426. [CrossRef]

23. Chee, C.Y.; Yong, G.K.; Abdullah, L.C.; Nadarajah, K. Effect of nanosilica and titania on thermal stability of polypropylene/oil palm empty fruit fibre composite. J. Biobased Mater. Bioenergy 2013, 7, 169-174. [CrossRef]

24. Jia, S.; Yu, D.; Zhu, Y.; Wang, Z.; Chen, L.; Fu, L. Morphology, Crystallization and Thermal Behaviors of PLA-Based Composites: Wonderful Effects of Hybrid GO/PEG via Dynamic Impregnating. Polymers 2017, 9, 528. [CrossRef] [PubMed]

25. Silverstein, R.M.; Webster, F.X.; Kiemle, D.J.; Bryce, D.L. Spectrometric Identification of Organic Compounds; John Wiley \& sons: Hoboken, NJ, USA, 2014. 
26. Nagarajan, V.; Zhang, K.; Misra, M.; Mohanty, A.K. Overcoming the fundamental challenges in improving the impact strength and crystallinity of PLA biocomposites: Influence of nucleating agent and mold temperature. ACS Appl. Mater. Interfaces 2015, 7, 11203-11214. [CrossRef] [PubMed]

27. Bakar, N.A.; Chee, C.Y.; Abdullah, L.C.; Ratnam, C.T.; Ibrahim, N.A. Thermal and dynamic mechanical properties of grafted kenaf filled poly (vinyl chloride)/ethylene vinyl acetate composites. Mater. Design (1980-2015) 2015, 65, 204-211. [CrossRef]

28. Cheng, S.; Lau, K.T.; Liu, T.; Zhao, Y.; Lam, P.M.; Yin, Y. Mechanical and thermal properties of chicken feather fiber/PLA green composites. Compos. Part B Eng. 2009, 40, 650-654. [CrossRef]

29. Huda, M.; Drzal, L.; Misra, M.; Mohanty, A. Wood-fiber-reinforced poly (lactic acid) composites: Evaluation of the physicomechanical and morphological properties. J. Appl. Polym. Sci. 2006, 102, 4856-4869. [CrossRef]

30. Hassan, E.; Wei, Y.; Jiao, H.; Muhuo, Y. Dynamic mechanical properties and thermal stability of poly (lactic acid) and poly (butylene succinate) blends composites. J. Fiber Bioeng. Inform. 2013, 6, 85-94.

31. Hassan, E.A.M.; Elagib, T.H.H.; Memon, H.; Yu, M.; Zhu, S. Surface Modification of Carbon Fibers by Grafting PEEK-NH2 for Improving Interfacial Adhesion with Polyetheretherketone. Materials 2019, 12, 778. [CrossRef]

32. Hassan, E.A.M.; Ge, D.; Yang, L.; Zhou, J.; Liu, M.; Yu, M.; Zhu, S. Highly boosting the interlaminar shear strength of CF/PEEK composites via introduction of PEKK onto activated CF. Compos. Part A Appl. Sci. Manuf. 2018, 112, 155-160. [CrossRef]

33. Hu, Q.; Zhang, Y.; Mao, Y.; Memon, H.; Qiu, Y.; Wei, Y.; Liu, W. A Comparative Study on Interlaminar Properties of L-shaped Two-Dimensional (2D) and Three-Dimensional (3D) Woven Composites. Appl. Compos. Mater. 2019, 26, 723-744. [CrossRef]

(C) 2019 by the authors. Licensee MDPI, Basel, Switzerland. This article is an open access article distributed under the terms and conditions of the Creative Commons Attribution (CC BY) license (http://creativecommons.org/licenses/by/4.0/). 